\title{
Minat Siswa Tunagrahita dalam Pembelajaran Pendidikan Jasmani
}

\author{
Mentally Retarded Students' Interest in Physical Education Learning
}

\author{
Akhmad Olih Solihin, Sriningsih, Diki \\ STKIP Pasundan, Cimahi, Jawa Barat, Indonesia \\ yoyoolih@gmail.com, sriningsihm33@gmail.com
}

\begin{abstract}
Abstrak
Penelitian ini bertujuan ingin mengetahui seberapa besar minat siswa tunagrahita dalam mengikuti pembelajaran pendidikan jasmani. Metode penelitian yang digunakan adalah metode pendekatan survey kuantitatif. Populasi yang digunakan dalam penelitian ini adalah seluruh siswa di SLB B/C Yatira Cimahi kelas Besar tahun ajaran 2015/2016 yang berjumlah 12 orang, terdiri dari 3 siswa tunarungu dan 9 siswa tunagrahita. Pemilihan sampel penelitian menggunakan teknik purposive sampling sehingga terpilih 9 orang siswa tunagrahita. Instrumen penelitian yang digunakan adalah angket tertutup. Hasil penelitian menunjukkan bahwa minat siswa tunagrahita dalam mengikuti pembelajaran pendidikan jasmani berada dalam bobot 11. Maka dapat diambil kesimpulan bahwa minat siswa dalam mengikuti pembelajaran pendidikan jasmani sangat tinggi.
\end{abstract}

Kata Kunci: Minat, Siswa Tunagrahita, Pendidikan Jasmani.

\begin{abstract}
This study aims to determine how much interest mentally retarded students are in participating in physical education learning. The research method used is a quantitative survey approach method. The population used in this study were 12 students in SLB B / C Yatira Cimahi for the 2015/2016 academic year, consisting of 3 deaf students and 9 mentally retarded students. The sample selection used $a$ purposive sampling technique so that 9 mentally retarded students were selected. The research instrument used was a closed questionnaire. The results showed that the interest of mentally retarded students in participating in physical education learning was in weight 11. So it can be concluded that the interest of students in participating in physical education learning is very high.
\end{abstract}

Keywords: Interests, Mentally Retarded Students, Physical Education 


\section{PENDAHULUAN}

Lembaga pendidikan SLB adalah lembaga pendidikan yang bertujuan membantu peserta didik yang menyandang kelainan fisik atau mental, perilaku dan sosial agar mampu mengembangkan sikap, pengetahuan dan keterampilan motoriknya sebagai pribadi maupun anggota masyarakat dalam mengadakan hubungan timbal balik dengan lingkungan sosial, budaya dan alam sekitar serta dapat mengembangkan kemampuan dalam dunia kerja atau mengikuti pendidikan lanjutan.

Adapun satuan pendidikan bagi anak berkebutuhan khusus mulai dari jenjang TKLB, SDLB hingga SMALB. Sedangkan jenis pendidikan Luar Biasa tersebut meliputi: SLB-A bagi peserta didik Tunanetra, SLB-B bagi peserta didik Tunarungu, SLB-C bagi peserta didik Tunagrahita, SLB-D bagi peserta didik Tunadaksa, SLB-E bagi peserta didik Tuna Laras, dan SLB-G bagi peserta didik Tuna Ganda. Tanggung jawab keberhasilan pendidikan anak-anak berkebutuhan khusus di sekolah terletak ditangan pendidik, yaitu guru SLB. Guru Pendidikan Luar Biasa selain mengajar, mereka juga berperan dalam membantu perkembangan anak didiknya. Selain itu Guru SLB dituntut untuk memiliki kesabaran yang tinggi, kesehatan fisik dan mental yang baik dalam bekerja (Rahmatullah \& Tj. K, 2013). Yang terpenting adalah mereka harus memiliki kinerjanya yang baik dan dan memiliki kompetensi dasar sebagai guru Pendidikan Luar Biasa (Anindhito, 2020; Kesumawati \& Damanik, 2019).

Pembelajaran penjas adaptif anak tunagrahita harus ada guru pendamping khusus atau GPK. Masing-masing GPK akan menjadi pendamping khusus untuk satu anak tunagrahita saat proses pembelajaran penjas adaptif. Materi yang diberikan oleh guru juga tidak boleh disamakan dengan siswa umum karena kebutuhan anak tunagrahita berbeda dengan siswa umum sehingga materi harus disesuaikan dengan kebutuhan anak tunagrahita (Anindhito, 2020; Syahruddin et al., 2017), Strategi mengajar penjas adaptif harus dimodifikasi oleh guru GPK.

Kondisi belajar mengajar yang efektif sendiri adalah adanya minat dan perhatian siswa dalam belajar (Darmawan, 2018), tetapi peneliti menemukan kejanggalan atau masalah ketika peneliti melaksanakan kegiatan pebelajaran penjas di SLB B/C Yatira Cimahi khususnya untuk anak yang berkebutuhan khusus tunagrahita seringkali peneliti melihat atau menemukan anak yang kurang semangat dalam mengikuti proses pembelajaran penjas.

Suatu minat dapat diekspresikan melalui suatu pernyataan yang menunjukan bahwa siswa lebih menyukai suatu hal daripada hal lainnya, dapat pula dimanifestasikan melalui partisipasi dalam suatu aktivitas, siswa yang memiliki minat terhadap subyek tertentu cenderung untuk memberikan perhatian yang lebih besar terhadap subyek tertentu (Slameto, 2015).

Sejatinya semangat atau minat siswa tersebut sangatlah berpengaruh terhadap capaian tujuan pembelajaran yang diinginkan (Astuti, 2015; Badaru, 2015). Semakin tinggi minat siswa maka 
semakin mudah tujuan pembelajaran tercapai, namun semakin rendah minat maka semakin sulit juga tujuan pembelajaran tercapai (Lestari, 2015).

Maka dari itu dalam penelitian ini peneliti berencana untuk mendapatkan bukti yang komprehensif mengenai sejauh mana minat siswa tunagrahita ringan dalam pembelajaran pendidikan jasmani.

\section{METODE}

Metode penelitian yang digunakan dalam penelitian ini adalah metode pendekatan survey kuantitatif (Sugiyono, 2017). Populasi yang digunakan dalam penelitian ini adalah seluruh siswa di SLB B/C Yatira Cimahi kelas Besar tahun ajaran 2015/2016 yang berjumlah 12 orang, terdiri dari 3 siswa tunarungu dan 9 siswa tunagrahita. Pemilihan sampel penelitian menggunakan teknik purposive sampling (Fraenkel \& Wallen, 2008), sehingga terpilih 9 orang siswa tunagrahita yang sesuai dengan kepeluan penelitian ini sendiri.

Instrumen penelitian yang digunakan berupa angket atau quesioner yang telah penulis kembangkan dan memiliki tingkat reliabilitas sebesar 0,996. Kemudian setelah data diperoleh penulis olah menggunakan aplikasi SPSS versi 18.

\section{HASIL DAN PEMBAHASAN}

\section{Hasil}

Hasil penelitian mengenai bobot minat siswa tunagrahita dalam pembelajaran pendidikan jasmani adaptif dapat dilihat pada tabel berikut:

Tabel 1. Bobot Variabel Minat Siswa Tunagrahita Ringan Dalam Mengikuti Pembelajaran Penjas

\begin{tabular}{lc}
\hline \multicolumn{1}{c}{ Indikator } & Jumlah bobot \\
\hline Perhatian & 152 \\
Kebutuhan & 99 \\
Perasaan Senang & 117 \\
\hline \multicolumn{1}{c}{ Jumlah } & 368 \\
\hline \multicolumn{1}{c}{ Rata-rata } & 11 \\
\hline
\end{tabular}

Dilihat dari tabel di atas bahwa bobot rata-rata variabel minat siswa tunagrahita ringan dalam mengikuti pembelajaran penjas 11 , nilai tersebut berada pada rentang $11-12$ atau berada pada kategori sangat tinggi. Artinya, minat siswa tunagrahita ringan SLB BC Yatira Cimahi dalam mengikuti pembelajaran penjas sangat tinggi.

\section{Pembahasan}

Pendidikan jasmani sejatinya memberikan nuansa tersendiri bagi siswa dalam kegiatan belajar mengajar di sekolah, tidak terkecuali bagi siswa yang berkebutuhan khusus. Pengalaman aktivitas 
gerak yang dikemas sedemikian rupa dan kegiatan yang dilaksanakan di luar kelas mampu menarik perhatian, minat, dan motivasi siswa untuk berpatisipasi aktif dalam kegiatan belajar pendidikan jasmani. Membaca buku, menulis, menghafal, berhitung, maupun aktivitas lain yang mereka lakukan selama pembelajaran lain di dalam kelas serontak akan membuat mereka mengalami kejenuhan, sehingga membuat minat dan motivasi mereka untuk belajar akan bekurang.

Melalui pendidikan jasmani juga, siswa dituntut agar aktif bergerak mengikuti materi yang disampaikan oleh guru. Hal tersebut akan berguna untuk meningkatkan kesehatan, kemampuan fisik, kognitif, afektif, maupun sosial siswa (Budiman et al., 2018). Tidak hanya di sekolah biasa pada umumnya, mata pelajaran pendidikan jasmani juga diajarkan di sekolah luar biasa yang disebut juga pelajaran pendidikan jasmani adaptif (Junanda \& Solihin, 2020) .

Aktivitas pembelajaran yang beda dari pelajaran yang lain tersebut mampu membuat siswa berkebutuhan khusus dalam hal ini siswa tunagrahita tertarik dan memiliki minat yang sangat tinggi untuk mengikuti pembelajaran penjas adaptif di sekolahnya. Namun perlu diketahui, tidak hanya mata pelajarannya saja yang mampu menarik minat siswa tersebut, hal yang penting lainnya yaitu bagaimana kompetensi guru untuk mengemas pelajaran penjas agar lebih efektif, efisien, dan menarik (Junanda \& Solihin, 2020; Solihin, 2016). Karena apabila guru tidak memiliki kompetensi tersebut, maka minat siswa akan belajar pendidikan jasmani akan berkurang.

Terlihat pada tabel 1 di atas, indikator yang paling dominan adalah indikator perhatian, diikuti indikator perasaan senang, dan yang paling rendah adalah indikator kebutuhan. Ini berarti kesadaran siswa akan pentingnya aktivitas pembelajaran pendidikan jasmani bukan menjadi pendorong utama minat mereka dalam pembelajaran.

\section{KESIMPULAN}

Berdasarkan hasil penelitian di atas maka dapat diperoleh kesimpulan bahwa tingkat minat siswa tunagrahita dalam mengikuti pembelajaran pendidikan jasmani sangat tinggi, dengan indikator utamanya yaitu perhatian, perasaan senang, dan terakhir adalah kebutuhan. Maka dari itu guru harus menyusun dan mengemas strategi yang sesuai dengan tingkatan indikator minat siswa agar minat mereka untuk belajar pendidikan jasmani semakin tinggi, sehingga akan lebih mudah bagi guru untuk mencapai tujuan pembelajaran.

\section{DAFTAR PUSTAKA}

Anindhito, Y. L. A. (2020). Pengembangan Model Permainan Olahraga Freeball pada Pembelajaran Penjas Adaptif Anak Tunagrahita di SLB Se-Kabupaten Kendal. Journal of Sport Coaching and Physical Education, 5(1), 68-75.

Astuti, S. P. (2015). Pengaruh Kemampuan Awal dan Minat Belajar terhadap Prestasi Belajar Fisika. 
Formatif: Jurnal Ilmiah Pendidikan $\quad$ MIPA, $\quad$ 5(1), https://doi.org/10.30998/formatif.v5i1.167

Badaru, B. (2015). Analisis Peranan Sarana dan Prasarana Penjasorkes Terhadap Minat Belajar Penjasorkes di SMA Negeri 10 Makassar. Jurnal ILARA, Ilmu Keolahragaan, Fakultas Ilmu Keolahragaan, Universitas Negeri Makassar, 6(1), 63-72. https://core.ac.uk/download/pdf/160742263.pdf

Budiman, A., Juliantine, T., \& Abduljabar, B. (2018). Student's Low Respect and Self-Regulation: is TPSR the Solution. Integrating Science and Technology in Developing Sport and Physical Education. Portugal: SCITEPRES.

Darmawan, S. (2018). Pengaruh Lingkungan Sekolah, Peran Guru Dan Minat Belajar Siswa Terhadap Motivasi Belajar Penjas Sd Inpres Buttatianang I Makassar. Jurnal Muara Pendidikan 3 (2), 103$111,3(2)$.

Fraenkel, J. R., \& Wallen, N. E. (2008). How to Design and Evaluate Research in Education (7th ed.). McGraw-Hill Higher Education.

Junanda, H. A., \& Solihin, A. O. (2020). Pengaruh media pembelajaran terhadap hasil belajar passing bawah bola voli pada siswa tunarungu. JPOE, 2(1), 76-85.

Kesumawati, S. A., \& Damanik, S. A. (2019). Model Pembelajaran Gerak Dasar pada Anak Tunagrahita Ringan. Jurnal Ilmu Keolahragaan, 18(2), 146-153.

Lestari, I. (2015). Pengaruh Waktu Belajar dan Minat Belajar terhadap Hasil Belajar Matematika. Formatif: Jurnal Ilmiah Pendidikan MIPA, 3(2), 115-125. https://doi.org/10.30998/formatif.v3i2.118

Rahmatullah, K., \& Tj. K, B. F. (2013). UPAYA PENINGKATAN KECEPATAN REAKSI ANAK TUNAGRAHITA KATEGORI SEDANG MELALUI PENDEKATAN PERMAINAN LEMPAR TANGKAP BOLA DI PENDIDIKAN KHUSUS NEGERI SEDURI-MOJOKERTO. Jurnal Pendidikan Olahraga Dan Kesehatan, 01(02), 368-371.

Slameto. (2015). Belajar dan Faktor-faktor yang Mempengaruhinya. PT. Rineka Cipta.

Solihin, A. O. (2016). Profil Tingkat Motivasi Siswa Tunarungu dalam Belajar Pendidikan Jasmani Adaptif. Jurnal Olahraga, 2(1), 9-16.

Sugiyono. (2017). Metode Penelitian Kuantitatif, Kualitatif dan R\&D. Alfabeta.

Syahruddin, S., Saleh, M. S., \& Rizal, A. (2017). Peningkatan Koordinasi Mata Tangan Melalui Model Pembelajaran Berbasis Bermain Bagi Anak Tuna Grahita. Seminar Nasional Lembaga Penelitian UNM, 2(1), 116-119. 